\title{
Development of Heat Power Economy of a Big City
}

\author{
Mamadov Mahabbat Ashir ${ }^{1}$, Aliyev Ruslan Yusif ${ }^{2}$, Mamadova Fidan Aliaga ${ }^{3}$, \\ Alizada Shahla Ibragim ${ }^{4}$ \\ Azerbaijan University Architecture and Construction, Azerbaijan ${ }^{1,2,3,4}$
}

\begin{abstract}
Experience of the developed countries of the world and Azerbaijan on providing of consumers with heat supply has been studied main stages of heat power economy development of big cities have been considered. Dynamics of heat consumption in the cities of Azerbaijan has been presented. While analyzing functioning of heat power economy criteria (indices) of efficiency have been used and generalized indices of efficiency of joint stock company have been presented.
\end{abstract}

Keywords: Heat Power Economy, Heat Supply, Energo-Resources, Index (Indicator), Prognosis

\section{INTRODUCTION}

In Azerbaijan economy heat power has significant importance. Wide-scale reforms have been realized to improve existing infrastructure and continuous providing of consumers with heat supply. As a result, at the expense of investing significant achievement have been gained in the field of heat supply. Currently there are 13 heat power stations in the country, the total power of which is $5132 \mathrm{mVt}$. In 2015 volume of heat power production was 427 th. Qcal in Azerbaijan, to 2020 it is envisaged to bring the volume to 1767 th, Qcal. Wherein, profit in 5.1 mln.manat will be provided.

In Azerbaijan counting on long-term perspective (after 2015) it is scheduled to use experience of advanced countries in the field heat supply. For it, priorities on each direction have been determined and concrete measures have been prepared. Further, for providing population and development of private sector gradual transfer of apart of heat supply to municipality is considered. In this case, experience of developed countries of the world, including Europe is studied in a wide scale. Due to the data of International Power Agency flats cooling, supply services with hot water, lightning, energy need in houses to prepare meals are about $40 \%$ of total energy supply [18].

Based on the report of the Environment Programme of HN on heat energy supply of buildings when using modern effective systems in this field, volume of energy supply in the world can be reduced 2 times to 2050 [8].

In some cities of the world, including Azerbaijan use of local resources (wind, solar energy, wastes and etc.) gives opportunity to provide consumers with cheap and qualitative heating services and also to minimize volumes of wastes and throw of harmful substances to the atmosphere. At the expense of the use of wind energy after 2025 probability of reduce of energy expenses can be 15-25\% [15]. For example, in the state Minnesota, USA, use of wood waste in heating system in municipality territory saves 275 tons coal a year which is 12 mln USA dollars [17].

In north America so-called roof variant of heat supply resources in the regions with dense city construction of such megapolices as Chicago, Detroyt and Cietle (USA), Toronto and Vancouver (Canada), roof boilers is $80 \%$ of total production of heat energy [9].

Roof resources of heat supply are used also in Azerbaijan, for example, in the suburb of Baku, in Shuvelan district on the roofs of schools and other objects. First solar batteries' with suitable efficiency transformation (about 6\%) were made by American scientists G.Rerson, K.Fuller and D.Chapin in 1953-1954. Russian scientists V.S.Vavilov, A.P.Landsman, N.S.Lidorenko, V.K.Subashev and American scientists M.Volf, J.Loferskiy, M.Prince, P.Rapoport made their contribution to the development of the theory and practice of solar elements [25]. Besides, in some cities of municipality part of heating systems was privatized. Thus, in Toronto (Canade) outcome is $89 \mathrm{mln}$. USA dollars at the expense of privatization of $43 \%$ of heat systems [7].

In world practice, significant attention is paid to the increase of power resources efficiency, especially in connection with the change of climatic conditions. It is necessary to mention experience of Khelsinki (Finland) on transfer of 83\% of annually produced electro energy to heating systems [16]. 


\section{International Advanced Research Journal in Science, Engineering and Technology}

Vol. 6, Issue 5, May 2019

Data on the cities of Azerbaijan testify that in comparison with European indices specific calculation of heat consumption on the heating of buildings is more than 2.5-3 times, but on specific heat consumption - approximately 4 times [27].

In the published works general scheme of the development of heat power economy of big cities of the world consists of three main stages: prognosis, programming and planning [21,23] analysis-prognosis-plan-author. That's why models and methods of prognosis have great significance in the process of preparing of scientifically justified planned solutions their application in heat power economy has particular significance in connection with relatively big of the process of the development in comparison with other fields. In the published works conception of role of prognosing in planning, ratio of plan and prognosis planning and economic prognosing hasn't been worked out up today. Three various points of view on the content of prognosis and their relation with planning. Due to the first approach, principal difference between planning and prognosing is determined by the time of the confirming of planning horizons $[1,10,24]$.

The second approach is that prognosis is considered as post plan stage of information processing and the following functions of prognoses related to planning are shown: determination of initial base of development of economy in planning period connected with the prognosis value of the fulfillment of the current period; justification of the choice of norms of development and inijustified solutions [11,6,20].

The third approach is connected with the analysis of the object of planning and prognosis. In this case, on the basis of division of planning and prognosis there is such fact that all processes in economics systems should be divided to controlled and uncontrolled. The role of prognosing is brought to the supply of the planning process of information on future development of uncontrolled (or weak controlled) characteristics of the processes, directly or indirectly influencing the result of planning (choice of development variant included into the plan), but not depending on the chosen variant $[4,5,25]$. Thus, so-called multi-optional prognosis evaluating advantages and disadvantages, compared variants of the plan are excluded from the prognizing sphere. Together with it, followers of the given direction [14,19] don't denj the necessity of such developments in the interests of compared evaluation of alternative variants of the plan, however they don't consider them prognosis as they don't contain objective forecasting of the future but they are determined by subjective factors-solution of which is made by the manager.

Multi-factor calculations on the determination of the results of influence on the economic process can be refered to conditional prognosis, that is to the prognosis which can be realized under the term of taking definite solution, first of all because consequences of the taking of these or those solutions are not determined. Besides there are methods and methodics on the basis of calculations traditionally referring to the methods of prognosis extrapolate of tendencies, multi-factor modeling of processes, expert methods and etc. Currently heat supply of a big city presents numerous group of interconnected and local enterprises in the system of urban economy [3].

Data of table 1 testify continuous growth of heat consumption in Azerbaijan cities. In connection with increasing volumes of industrial production and building construction in the regions, not occupied with heat supply from TEC, the necessity of creation of local heat sources notice are district and region power stations (QHS) [16].

Planning and designing of centralized heat supply systems, especially big ones, and also urban syntering (industrial area complexes) are important complex problem, from their right solution both scales of necessary investments on the engineering equipment of the developing cities, and creation of necessary labour and everyday conditions for population of these cities depend on (Martin Clode, 1995)

Table 1: Dynamics heat consumption in the country

\begin{tabular}{|l|c|c|c|c|c|}
\hline \multicolumn{1}{|c|}{ Indices } & Measure unit & 2005 & 2010 & 2015 & 2020 \\
\hline Heat consumption of the cities: & & & & & \\
\hline From HEC & $\%$ & 41.3 & 41.8 & 42.5 & 43.1 \\
\hline Regional and district boilers & also & 27.2 & 32.0 & 37.2 & 40.7 \\
\hline Small boilers & also & 31.5 & 26.2 & 20.3 & 16.2 \\
\hline specific heat consumption & gJ/man a year & 16.3 & 18.8 & 21.8 & 23.9 \\
\hline $\begin{array}{l}\text { Level of housing fond of cities and } \\
\text { districts, availability in the system: }\end{array}$ & & & & & \\
\hline Heating & $\%$ & 32.6 & 40.1 & 43.2 & 44.5 \\
\hline Hot water supply & & 2.4 & 3.2 & 5.6 & 6.7 \\
\hline
\end{tabular}

Source: the table is worked out by the author due to the materials of "Azerheatsupply" and Ministry of Economic development. 


\section{International Advanced Research Journal in Science, Engineering and Technology}

Vol. 6, Issue 5, May 2019

When analyzing functioning heat power economy it is necessary to use some criteria of efficiency, including indices of productivity of labour, fund return, cost [20]. The author adhers to such an approach.

Efficiency and quality of the accepted planned and administrative solutions considerably depend on the choke of indices included into the system of analysis, planning and control [13].

Investigated joint stock is presented in the form of the system having inlet, outlet, processor for making easy formation of the content of initial indices meeting principle of the systematic approach to the analyzed object Correspondingly, in the estimation group, indices must be so that to reflect all parts of the system. The content of the indices reflecting "inlet" is the following: it is realized by heat energy, it is produced by heat energy, the number of the inhabitants supplied by heat energy and hot water. Indices of main industrial funds, quality of boilers, quality of CHS (central heat stations, length of heat nets are included into the group of indices reflecting processor. As indices reflecting "inlet" the followings were chosen: fund of salary; volume of repair, cost consumption of gas, water electro energy, average number of employees.

Thus, 15 indices entered the group of estimation meeting principle of information filter, besides 3 . its absence is caused by that not all of the indices are presented in the form of components of their indices very often one line determines all aggregated index, but the other is its more important component, for example, index of salary fund having independent role in the control process has been shown from cost index. As criteria of assessment indices analysis for getting total assessment the ranging - determination of the level of importance including into the group of indices has been used. Their weight has been determined on the basis of the obtained ranges as a result of assessment on the importance scores of each index of the group.

Ranging of indices inside the group is carried out on the methodics of paired comparisons [22];

- table 15x15, is made up in the lines and schedules of which indices of assessment group have been arranged;

- priorities are determined by the method of paired comparisons. If index in the line must have big growth rate than index in the line of corresponding cell, then sign "+" is written, or vice versa, "-“, if growth rates due to expert's view are the same - " 0 ";

- $\quad$ after the filling the table, the sum of offers on each index (sum "+" on the lines) and the sum of refuses (sum "-_)

- $\quad$ on the lines. Indices are placed on the decrease of their priorities determined by the sum of gained scores.

Criteria of efficiency is made up on the basis of that concept that, for the intensive growth of efficiency it is necessary that result growth rates were ahead of growth rates of used resources [6].

For each pair of indices preference given to the growth rates or indifference can be determined experimentally. After generalization of these preferences the standart ranked number of indices (SRI) has been obtained where these indices have been placed in the diminishing order of the growth rates. Such order will be generalization of all existing private criteria of efficiency since all reflected proportions between private indices will be observed in them. Dividing the rank of each index to the total sum of rank it is possible to get weight coefficient of this index in the general system of indices of joint stock activity. Formation of SRI in the common form takes place so: on the first place results, on the second place-processors, on the third place - resource indices have been placed. SPI obtained on the basis of expert values is shown on table 2 .

Table 2: SPI obtained on the basis of expert values

\begin{tabular}{|l|c|l|c|}
\hline Rank & Number of index & index & Weight coefficients \\
\hline I & 1 & Realization of heat energy & 1 \\
\hline II & 2 & Produced by heat energy & 0.765 \\
\hline III & 3 & Quantity of CHP & 0.532 \\
\hline IV & 4 & Extent of heat mets & 0.498 \\
\hline V & 5 & Gas consumption & 0.401 \\
V & 6 & Water consumption & 0.401 \\
V & 7 & Electric power consumption & 0.401 \\
\hline VI & 8 & Number of inhabitants using and hot water & 0.395 \\
\hline VII & 9 & Number of boilers & 0.310 \\
VII & 10 & Volume of work over & 0.310 \\
\hline VIII & 11 & Main industrial funds & 0.293 \\
\hline IX & 12 & Number of employers & 0.215 \\
\hline X & 13 & Cost & 0.112 \\
\hline XI & 14 & Salary fund & 0.105 \\
\hline XII & 15 & AYP number & 0.032 \\
\hline
\end{tabular}

Source: the table is compiled by the author on Azerheatproviding materials. 


\section{International Advanced Research Journal in Science, Engineering and Technology}

Vol. 6, Issue 5, May 2019

If SPI in a general form can be used for strategic planning of joint stock in a whole, then for subdivisions it is required to bring SPI of general form to partial SPI. For bringing SPI of general for to the partial SPI expert questioning and also preliminary analysis of technico-economic level have been applied. Analysis of growth rates of main indices is carried out on the basis of Joint stock "Azerheatsupply" example-generalizing criteria of efficiency by I.M.Sirayejin. This criteria is built on the basis of comparison of factice and standart work regimes mathematical evaluation of their correspondence as apparatus of mathematical evaluation, range correlation allowing to determine similarity of ranged rows of induces is used.

For evaluation of efficiency of joint stock activity:

- factual and planned growth rates relatively to all indices entering into the system are calculated, for which level of n-years is brought to the base year lever Besides, factual and planned growth rates on all indices entering the system are calculated;

- obtained factual and planned values of the indices are ranged on the following rates;

- more is the growth rate, bigger is the range accepting one as a bigger range, and the following values of the numbers of natural row-as diminishing ranges;

- ranges of factual and planned system of SPI indices are compared and on the basis of this comparison the coefficients of Spirmen's and Kendell range correlation are calculated [22].

$$
K_{C}=1-\frac{6 \sum_{S=1}^{N} X_{S}^{2}}{N\left(N^{2}-1\right)}, \quad\left(-1, K_{C}<+1\right)
$$

where $X_{S}$ - is the difference between factual (planned) and standart, $N-$ is the quantity of indices included into SPI Kendell coefficient is based on the counting of the number of the indices having bigger factual range than considered index, but in addition normative range is smaller than the considered one. Such position of the index is called inversion.

$$
K_{K}=1-\frac{4 \sum_{S=1}^{N} X_{S}}{N\left(N^{2}-1\right)}, \quad\left(-1, K_{K}<+1\right)
$$

where $X_{S}-$ is number of inversions of Sindex; $N-$ is the quantity of indices included into SPI.

In complete correspondence of factual and normative rows of $\mathrm{K}_{\mathrm{C}}$ and $\mathrm{K}_{\mathrm{K}}$ values +1 are accepted, in complete disperancy -1 .

Two indices have been used in I.M.Sirogejin methodics and has offered the following formula for generalizing the value

$$
K=\frac{\left(1+K_{C}\right)\left(1+K_{K}\right)}{4}
$$

For simplified calculation one of the indices can be used, for example Spirmen's coefficient which is based on the sum of the squares of the decline and reflects absolute disperancy between two rows of numbers. On the basis of report documentation of open joint stock company "Azerheatsupply" for 2005 - 2016 - s planned and factual growth rates were calculated relatively to basis of 2005 and preceding year. The obtained values have been ranged on the principle - the more is the index, the bigger is the range.

Due to each ranged row the value of the generalized index of efficiency has been determined on the basis of Spermen's coefficiency by the comparison with rational SPI calculated for joint stock Company "Azerheatsupply" based on expert questioning presented in table 3 .

Table : Quantity of generalized efficiency index

\begin{tabular}{|l|l|l|l|l|l|l|l|l|l|l|}
\hline & 2000 & 2005 & 2006 & 2010 & 2011 & 2012 & 2013 & 2014 & 2015 & 2016 \\
\hline 1.Relatively to 2000 base \\
\hline Plan & 0.40 & 0.59 & 0.50 & 0.56 & 0.62 & 0.61 & 0.62 & 0.64 & 0.67 & 0.65 \\
\hline Fact & 0.50 & 0.48 & 0.61 & 0.51 & 0.50 & 0.58 & 0.54 & 0.58 & 0.62 & 0.60 \\
\hline 2. Relatively to preceding year \\
\hline Plan & 0.27 & 0.44 & 0.55 & 0.49 & 0.45 & 0.72 & 0.71 & 0.73 & 0.76 & 0.77 \\
\hline Fact & 0.51 & 0.61 & 0.44 & 0.26 & 0.40 & 0.84 & 0.76 & 0.78 & 0.81 & 0.83 \\
\hline
\end{tabular}




\title{
International Advanced Research Journal in Science, Engineering and Technology
}

\author{
Vol. 6, Issue 5, May 2019
}

\section{CONCLUSION}

As a result assessment of factical and planned efficiency of the activity of joint stock company relatively to 2005 base and dynamic one-relatively to preceding year considered for 2005 - 2016 has been obtained. Comparison with the base allows to smooth annual efficiency fluctuations, to assess general tendencies. For the operative control it is better to use current efficiency. Presented methodics allows numerically to assess disproportions in the tendencies of indices of joint stock company development and based on the analysis to work out recommendations on their improvement or liquidation.

\section{REFERENCES}

[1]. Kalam, A., King, A., Moret, E. and Weerasinghe, U. (2012). Combined heat and power systems: economic and policy barriers to growth. Chemistry Central Journal, 6(Suppl 1), p.S3.

[2]. Sperling, K. and Moller, B. (2012). End-use energy savings and district heating expansion in a local renewable energy system - A short-term perspective. Applied Energy, 92, pp.831-842.

[3]. Wissner, M. (2014). Regulation of district-heating systems. Utilities Policy, 31, pp.63-73.

[4]. Lund, H., Moller, B., Mathiesen, B. and Dyrelund, A. (2010). The role of district heating in future renewable energy systems. Energy, 35(3), pp.1381-1390.

[5]. Persson, U. and Werner, S. (2011). Heat distribution and the future competitiveness of district heating. Applied Energy, 88(3), pp.568-576.

[6]. Latosov, E., Volkova, A., Siirde, A., Kurnitski, J. and Thalfeldt, M. (2017). Methodological Approach to Determining the Effect of Parallel Energy Consumption on District Heating System. Environmental and Climate Technologies, 19(1).

[7]. Mekshun, L. (2016). Current trends of housing and communal services management reform under decentralization in Ukraine. Scientific bulletin of polissia, (1), pp.30-36.

[8]. Zhou, B., Li, W., Chan, K., Cao, Y., Kuang, Y., Liu, X. and Wang, X. (2016). Smart home energy management systems: Concept, configurations, and scheduling strategies. Renewable and Sustainable Energy Reviews, 61, pp.30-40.

[9]. Beaudin, M. and Zareipour, H. (2015). Home energy management systems: A review of modelling and complexity. Renewable and Sustainable Energy Reviews, 45, pp.318-335.

[10]. Shulepina, S. A. (2015). The state and development of housing and communal sector of Russia, Eurasian journal of economic and finance, 3(3), 65-71. http://dx.doi.org/10.15604/eief.2015.03.03.006

[11]. Buzdugan, A. (2013). Ways to Optimize the Labourin the Communal Housing Complex. Economie Si Sociologie: Revista Teoretico-Stiintifica. Institutul National De Cercetari Economice, 169-178

[12]. Shulepina, S. A. (2015). The state and development of housing and communal sector of Russia, Eurasian journal of economic and finance, 3(3), 65-71. http://dx.doi.Org/1 0.15604/eief.2015.03.03.006

[13]. Agapitova, E., Chahkiev, G. and Gerasimova, V. (2017). The factors to assess the quality of management of housing and communal services. MATEC Web of Conferences, 106, p.08075.

[14]. Bakker, V., Molderink, A., Hurink, J. and Smit, G. (2008). Domestic Heat Demand Prediction Using Neural Networks. 2008 19th International Conference on Systems Engineering.

[15]. International standarts of MSO assessment MK SOI-M.: 1995

[16]. Meskon M.Kh., Albert M. Chodouri F. Management basis: M.: Delo, 2000

[17]. Oxford dictionary on business. M., 1995

[18]. Assessment of estate cost. Experience of African Institute on estate assessment. M: 1993

[19]. Rozenberg D. Terminology dictionary Tootsgers University (USA), M.: 1992

[20]. Strategical rood map of development and housing supply on the corresponding prices in Azerbaijan Republic. Baku, 2016

[21]. Timonina I. Yaponiya: Experienci of regional developmeni. M.: Nauka, 1992

[22]. Fatullayev Sh. House building in Azerbaijan in XIX-XX Baku, AS of Azerbaijan SSR, 1968, 119 pp.

[23]. Freedman J., Orduey N. Analysis and assessment resulting in estate income. M.: Delo LTD, 1995

[24]. Charrison Hery S. Estate assessment M.: "Mosoblpoly-graphirdat" 1994

[25]. Tsukerman G. Avard N., Blivins J.J. Estate. M.: JS Theme, 1994

[26]. Shakaraliyev A.Sh., Asaul A.N., Denisivora I.V., Orudjev T.K., Mustafayev F.F. Estate economics. Textbook, Baku, 2004

[27]. Shiraliyev V.M. Development of hiusing duilding in Azerbaijan Baku "Elm" 2008, pp.215 